\title{
Management, Complications and Outcomes of 14 Cases of Cesarean Scar Pregnancy in a Tertiary Care Hospital in Sri Lanka
}

\author{
Dodampahala $\mathrm{SH}^{1}$, Dodampahala $\mathrm{SK}^{2}$, Dodampahala $\mathrm{SD}^{3}$ \\ ${ }^{1}$ Associate professor, Department of Obstetrics and Gynaecology, Faculty of Medicine, University of Colombo, Colombo, Sri Lanka \\ ${ }^{2,3}$ Undergraduate Research Student
}

\begin{abstract}
Morbidly adherent placenta (MAP) is an umbrella term used to refer to abnormally invasive placentation further divided as placenta accrete, increta and percreta. In the presence of MAP, normal placental separation may fail to occur leading to increased perpartum blood loss and hysterectomy. With the increase in cesarean deliveries, the main risk factor for MAP, the incidence of the condition has increased and likely continue to do so in the near future. In this case series we describe the management and outcomes of 14 patients with MAP presenting to a single unit at a tertiary care hospital in Sri Lanka. Antenatal diagnosis using history and ISUOG ultrasound diagnostic criteria, preparation of detailed management plans in accordance with latest international recommendation and close supervision of the Consultant Obstetrician during operative management were the mainstays of management. Through this, the unit was able to maintain $100 \%$ maternal survival.
\end{abstract}

Keywords: morbidly adherent placenta, placenta accrete, placenta increta, placenta percreta

\section{Introduction}

Morbidly adherent placenta (MAP) is a term that encompasses placenta accreta, increta and percreta [1] which represent the three forms of abnormally invasive placental implantation [2]. It is thought to result from defective decidualization at the implantation site [3] due to previous scarring. Placenta accreta, is the commonest and the least severe form of MAP where the invasion of placental villi is limited to the surface of the uterine myometrium [2]. In placenta increta, the uterine villi invade in to the myometrium while in percreta, the villi pierce through the myometrium and may invade the adjacent organs including the urinary bladder [2]. Due to this abnormal invasion, MAP leads to failure of spontaneous placental separation resulting in severe peri-partum blood loss [4] which can eventually lead to hysterectomy. MAP has been shown to be associated with high fetomaternal morbidity and mortality [5].

Main risk factors for MAP include previous cesarean section $[5,6]$, endometrial infection, uterine procedures leading to scarring as well as the presence of placenta previa and advanced maternal age $[5,6]$. The incidence of MAP, particularly placenta accreta, has seen a significant increase in the recent years in parallel with the rapid increase in the number of cesarean sections [1,6]. As a result placenta accreta is now recognized as the leading cause of pot-partum hemorrhage [7] as well as peri-partum hysterectomy [8] in the world. Accurate pre-natal diagnosis followed appropriate surgical intervention is the mainstay in reducing adverse maternal and fetal outcome $[1,8]$ due to placenta accreta and other forms of MAP. Diagnosis can often be made using ultrasonography while MRI may be used in the more complex cases [1]. If an early diagnosis can be made, delivery is usually carried out by before term through planned cesarean section (CS) to avoid the need for and complications associated with emergency CS [8].
Sri Lanka is South Asian country belonging to the lower middle income category that has a strong, state sponsored healthcare system that provides free healthcare to all citizens. Maternal mortality rate in the country has been steadily declining since 1995 and stood at 29 death per 100000 live births by the year 2013 [9], a figure that is by far the best in the region. By 2012, both the institutional delivery rate and skilled attendance at the time of delivery was over $98 \%$ $[10,11]$. However, with these advances, the percentage of cesarean deliveries in the country has also increased significantly [12]. By 2012, 23.8\% of all deliveries in the country were through cesarean section, a figure that is roughly three times that of neighboring India and Pakistan and is nearly equivalent to the rate of CS in UK during the same period [11]. With this increase in the rate of cesarean delivery, it is justifiable to expect a parallel increase in the number of cesarean section related pregnancy complications including scar pregnancy and variants of MAP. However, there is a paucity of data regarding MAP and its' management.The objective this case series is to analyze the maternal characteristics, diagnostic criteria, surgical complications, their management and neonatal outcomes in relation to patient diagnosed with MAP in a single tertiary care center in Sri Lanka. Authors hope that the study will broaden understanding of this rising problem in the lower middle income setting and prove the first step for more comprehensive approach to improving outcome of cesarean section related MAP.

\section{Methods}

In this paper we describe 14 cases of cesarean scar pregnancy/MAP that presented to a leading tertiary care hospital in Sri Lanka between during a 2 year period between $1^{\text {st }}$ January 2012 to $31^{\text {st }}$ December 2013 . Two of the patients included in the study were diagnosed with morbidly placenta accreta during emergency cesarean section while the remaining 12 were diagnosed antenataly either during late

Volume 4 Issue 12, December 2015 


\section{International Journal of Science and Research (IJSR) \\ ISSN (Online): 2319-7064}

Index Copernicus Value (2013): 6.14 | Impact Factor (2014): 5.611

$2^{\text {nd }}$ trimester or early $3^{\text {rd }}$ trimester using ISUOG criteria for ultrasonic diagnosis of morbidly adherent placenta.

1) Thickness of the previous scar

2) Sinuses

3) Presence of Doppler signals in the bladder

All patient were enrolled for the study following informed written consent. Antenataly diagnosed patients were counselled regarding their condition and the associated risks and complications and advised regarding the need for submitting to close follow up and vigilance on the part of the mother to ensure maximum chance of favorable pregnancy outcome. Two of the mothers presented to the emergency department with no prior diagnosis of MAP.

Mothers who were antenataly diagnosed were closely followed up until the completion of pregnancy with 2 weekly ultrasound scans to assess and ensure feto-maternal wellbeing. The timing of delivery was determined based on the fetal maturity and development of complications such as antepartum hemorrhage and subsequent complications. In the absence of antepartum hemorrhage, fetal growth restriction, fetal distress and any maternal complications, pregnancies were extended up to 38 weeks. Unlike in some countries, termination of pregnancy as an option was not offered to any of the patients due to the existing legislature in the country that strictly controls the circumstances regarding termination of pregnancy. Following standard procedures and unit policy, each patients was further advised regarding specific complications of cesarean delivery including risk of hemorrhage and need for hysterectomy and informed consent was obtained prior to surgery. Data collection was done prospectively and data was extracted using the clinic records and the bed-head tickets of the patients. All deliveries documented in this report were carried out under the direct supervision of Consultant Obstetrician and Gynaecologist.

\section{Ethical Clearance}

Ethical clearance for the study was obtained from the ethical committee of the De Soyza Maternity Hospital.

\section{Results}

The ages of the 14 patients enrolled in the study ranged from 28-40 years. Twelve of the patients were antenataly diagnosed with morbidly adherent placenta based on clinical history, symptomatology and ultrasound findings (based on ISUOG criteria) while the other two were diagnosed at the time of emergency-cesarean section. Detailed management plans were in-place for the antenataly diagnosed patients.

With the exception of one, all other patients in the study were in their $3^{\text {rd }}$ or later pregnancy while $13(93 \%)$ had a past history of at least one cesarean section. A majority of the patients $(n=8,57 \%)$ had a low lying placenta and antepartum hemorrhage $(\mathrm{APH})$ was the most prevalent antenatal complication $(n=5,35 \%)$. All patients (12) who were antenataly diagnosed, fulfilled at least one ISUOG criterion for the diagnosis of MAP. The remaining two patients were only diagnosed at the time of delivery. Table 1 summarizes the antenatal finding of the patients enrolled in the study.

Table 1Details of the patients enrolled in the study.

\begin{tabular}{|c|c|c|c|c|c|c|}
\hline No. & Age (Years) & Parity & Past obstetric history & Antenatal complications & Placental location & ISUOG criteria fulfilled \\
\hline 01 & 28 & $\mathrm{P}^{1}, \mathrm{C}^{2}$ & 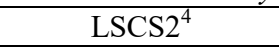 & $\mathrm{APH}^{5}$ & Placenta previa & $1 \& 2$ \\
\hline 02 & 34 & P3, C2 & LSCS 2 & $\mathrm{PIH}^{6}$ & Placenta previa & $1,2 \& 3$ \\
\hline 03 & 33 & $\mathrm{P} 3, \mathrm{C} 2$ & LSCS 1 & \multicolumn{3}{|c|}{ Diagnosed at the time of delivery } \\
\hline 04 & 36 & P3, C2 & LSCS2 & Pain & Placenta previa & 1 \\
\hline 05 & 40 & P3, C2 & LSCS2 & $\mathrm{APH}$ & Placenta previa & $1,2 \& 3$ \\
\hline 06 & 35 & $\mathrm{P} 4, \mathrm{C} 3$ & LSCS1 & & Anterior & 1 \\
\hline 07 & 33 & $\mathrm{P} 3, \mathrm{C} 2$ & LSCS2 & IDA $^{7}$ & Placenta previa & $1,2 \& 3$ \\
\hline 08 & 33 & $\mathrm{P} 1, \mathrm{C} 1$ & & $\mathrm{IUD}^{8}$ & Anterior & 1 \\
\hline 09 & 36 & P6, C2 & LSCS2 & \multicolumn{3}{|c|}{ Diagnosed at the time of delivery } \\
\hline 10 & 36 & P3, C2 & LSCS2 & & Anterior & $1 \& 2$ \\
\hline 11 & 35 & $\mathrm{P} 3, \mathrm{C} 2$ & LSCS2 & $\mathrm{APLS}^{9}, \mathrm{APH}$ & Placenta previa & $1 \& 2$ \\
\hline 12 & 39 & $\mathrm{P} 4, \mathrm{C} 2$ & LSCS1 & $\mathrm{GDM}^{10}$ & Placenta previa & $1,2 \& 3$ \\
\hline 13 & 37 & $\mathrm{P} 3, \mathrm{C} 2$ & LSCS2 & IDA $^{7}$ & LSCS2 & $1 \& 2$ \\
\hline 14 & 34 & P3, C2 & LSCS2 & $\mathrm{APH}$ & LSCS2 & $1,2 \& 3$ \\
\hline
\end{tabular}

1. $\mathrm{P}=$ Pregnancy

2. $\mathrm{C}=$ Children (living)

4. $\mathrm{LSCS}=$ Lower segment cesarean section

5. $\mathrm{APH}=$ Antepartum Hemorrhage

6. $\mathrm{PIH}=$ Pregnancy induced hypertension

7. IDA $=$ Iron Deficiency Anemia

8. IUD $=$ Intra-uterine death

9. APLS = Antiphospholipid syndrome

10. $\mathrm{GDM}=$ Gestational diabetes mellitus

All patients delivered through cesarean section at gestational ages ranging from 35 to 37 weeks. There were a total of six emergency cesarean sections. Blood loss following delivery ranged from $700 \mathrm{ml}$ to $2500 \mathrm{ml}$ and total-abdominal hysterectomy (TAH) was performed in all patients. Additionally, internal iliac artery ligation was also performed

\section{Volume 4 Issue 12, December 2015}




\section{International Journal of Science and Research (IJSR) \\ ISSN (Online): 2319-7064}

Index Copernicus Value (2013): 6.14 | Impact Factor (2014): 5.611

on 10 of the mothers and internal iliac artery embolization was performed on further 3. There were no maternal casualties. However, 3 neonatal deaths were observed, two of which were observed in neonates with severe IUGR. Table 2 summarizes the details regarding delivery and outcome of the 14 mothers

Table 2: Details regarding delivery and outcome of mother and the neonate

\begin{tabular}{|c|c|c|c|c|c|c|}
\hline No & Delivery & $\begin{array}{c}\text { Surgical } \\
\text { intervention }\end{array}$ & Blood loss & $\begin{array}{l}\text { Internal iliac artery } \\
\text { ligation }\end{array}$ & $\begin{array}{c}\text { Outcome of the } \\
\text { mother }\end{array}$ & Outcome of the fetus \\
\hline 01 & $34 \mathrm{EM} \mathrm{LSCS}^{1}$ & $\mathrm{TAH}^{3}$ & $2000 \mathrm{ml}$ & YES & GOOD & GOOD \\
\hline 02 & 35 EL LSCS $^{2}$ & TAH & $1000 \mathrm{ml}$ & YES & GOOD & GOOD \\
\hline 03 & 32 EM LSCS & LATE TAH & $2000 \mathrm{ml}$ & NO & GOOD & $\mathrm{NND}^{5}$ \\
\hline 04 & 35 EL LSCS & TAH & $1000 \mathrm{ml}$ & YES & GOOD & GOOD $\left(\right.$ IUGR $\left.^{6}\right)$ \\
\hline 05 & 35 EM LSCS & TAH & $1000 \mathrm{ml}$ & YES & GOOD & GOOD \\
\hline 06 & 36 EL LSCS & TAH & $750 \mathrm{ml}$ & $\mathrm{NO}$ & GOOD & GOOD \\
\hline 07 & 35 EL LSCS & TAH & $1000 \mathrm{ml}$ & YES & GOOD & GOOD \\
\hline 08 & 35 EL LSCS & TAH & $2000 \mathrm{ml}$ & $\mathrm{EMB}^{4}$ & GOOD & GOOD \\
\hline 09 & 30 EM LSCS & TAH & $1500 \mathrm{ml}$ & EMB & GOOD & NND (IUGR) \\
\hline 10 & 36 EL LSCS & TAH & $700 \mathrm{ml}$ & EMB & GOOD & GOOD \\
\hline 11 & 30 EM LSCS & TAH & $1500 \mathrm{ml}$ & YES & GOOD & NND (IUGR) \\
\hline 12 & 37 EL LSCS & TAH & $2500 \mathrm{ml}$ & YES & GOOD & GOOD \\
\hline 13 & 34 EL LSCS & TAH & $750 \mathrm{ml}$ & YES & GOOD & GOOD \\
\hline 14 & 33 EM LSCS & TAH & $1000 \mathrm{ml}$ & YES & GOOD & GOOD \\
\hline
\end{tabular}

1. EM LSCS = Emergency lower segment cesarean section

2. EL LSCS = Elective lower segment cesarean section

3. $\mathrm{TAH}=$ Total abdominal hysterectomy

4. $\mathrm{EMB}=$ Embolization (of the anterior iliac artery)

5. $\mathrm{NND}=$ Neonatal death

6. IUGR $=$ Intrauterine growth retardation

Careful antenatal screening of high risk mothers, detailed management plans, involvement of the consultant in decision making and surgical interventions along with careful preparation for complications including cross matching of blood were employed during the management of these patients. All elective cesarean sections were planned with consideration to availability of consultant supervision.

All surgical interventions were carried out by consultant obstetricians with the assistance of specialist registrars.

\section{Discussion}

The main purpose of the case series presented above was to detail the management practices and outcomes of patients with MAP in a tertiary care setting in Sri Lanka. Twelve of the fourteen mothers with MAP were diagnosed antenataly while two were only diagnosed at the time of delivery. Antenatal ultrasound screening, based on ISUOG criteria, supplemented by clinical history allowed this high rate of antenatal diagnosis. Antenataly diagnosed mothers were counselled regarding their condition. Two of the mothers needed iron supplementation following the detection of iron deficiency anemia.

All elective cesarean deliveries were carried out between $35^{\text {th }}$ to $37^{\text {th }}$ week of gestation as suggested by recent literature on the topic [13-15] and were performed under consultant supervision. The high rate of antenatal diagnosis and consultant involvement in surgical management can be considered as the primary reasons for the $100 \%$ maternal survival rate. Of the 3 neonatal deaths that occurred, two were at least partially attributable to the presence of severe IUGR.

During surgical intervention, we relied upon the ligation of the anterior division of the internal illiac artery using simple dissection and the use of aneurism needle was very handy in all our procedures, all ligations were successfulwithout any evidence of ischemia, perineal de-vascularization, and operative injury to internal iliac vein. However except in the case of 3 mothers, the blood loss in all other cases were $1000 \mathrm{ml}$ or greater.

\section{Conclusions}

The results of the 14 cases clearly indicate that proper antenatal assessment,correct ultrasound diagnosis, follow up anticipating possible adverse outcomes like APH, skilled operative interference (with consultant involvement), right timing and presence of blood and blood products has helped dramatically to prevent maternal deaths and perinatal deaths, even in the low resource healthcare setting.

\section{References}

[1] A. Abuhamad, "Morbidly adherent placenta," Semin. Perinatol., vol. 37, no. 5, pp. 359-364, Oct. 2013.

[2] K. E. Fitzpatrick, S. Sellers, P. Spark, J. J. Kurinczuk, P. Brocklehurst, M. Knight, "The management and outcomes of placenta accreta, increta, and percreta in the UK: a population-based descriptive study," Bjog, vol. 121, no. 1, pp. 62-71, Jan. 2014.

[3] P. Tantbirojn, C. Crum and M. Parast, "Pathophysiology of Placenta Creta: The Role of Decidua and ExtravillousTrophoblast", Placenta, vol. 29, no. 7, pp. 639-645, 2008.

[4] S. Collins, A. Ashcroft, T. Braun, P. Calda, J. LanghoffRoos, O. Morel, V. Stefanovic, B. Tutschek, F. Chantraine, "Proposal for standardised ultrasound descriptors of abnormally invasive placenta (AIP)", Ultrasound ObstetGynecol, 2015.

\section{Volume 4 Issue 12, December 2015}




\section{International Journal of Science and Research (IJSR) \\ ISSN (Online): 2319-7064}

Index Copernicus Value (2013): 6.14 $\mid$ Impact Factor (2014): 5.611

[5] R. Aggarwal, A. Suneja, N. B. Vaid, P. Yadav, A. Sharma, K. Mishra, "Morbidly Adherent Placenta: A Critical Review," J. Obstet. Gynaecol. India, vol. 62, no. 1, pp. 57-61, Feb. 2012.

[6] S. WU, M. Kocherginsky and J. Hibbard, 'Home PubMed - NCBI', Ncbi.nlm.nih.gov, 2015. [Online]. Available: $\quad$ http://www.ncbi.nlm.nih.gov/pubmed. [Accessed: 19- Nov- 2015].

[7] W. Goh and I. Zalud, "Placenta accreta: Diagnosis, management and the molecular biology of the morbidly adherent placenta.", J Matern Fetal Neonatal Med, pp. 129, 2015.

[8] G. Garmi and R. Salim, "Epidemiology, Etiology, Diagnosis, and Management of Placenta Accreta," Obstet. Gynecol. Int., vol. 2012, p. 873929, May 2012.

[9] World Health Organization, 'Maternal mortality in 19902013 WHO, UNICEF, UNFPA, The World Bank, and United Nations Population Division Maternal Mortality Estimation Inter-Agency Group Sri Lank', 2015. [Online]. Available: http://www.who.int/gho/maternal_health/countries/lka.p df?ua=1. [Accessed: 24- Nov- 2015]

[10] UNICEF, "State of the World's Children 2009”. New York: United Nations Children's Fund, p. 21, 2009.

[11]UNICEF, “Country Statistics", 2015. [Online]. Available http://www.unicef.org/statistics/index_countrystats.html. [Accessed: 24- Nov- 2015].

[12]M. Goonewardene, D. Kumara, D. Arachchi, R. Vithanage, R. Wijeweera, "The rising trend in caesarean section rates: should we and can we reduce it?",Sri Lanka Journal of Obstetrics and Gynaecology, vol. 34, no. 1, 2012.

[13]B. Robinson, W. Grobman, "Effectiveness of Timing Strategies for Delivery of Individuals With Placenta Previa and Accreta", Obstetrics \& Gynecology, vol. 116, no. 4, pp. 835-842, 2010.

[14] C. Spong, B. Mercer, M. D’Alton, S. Kilpatrick, S. Blackwell, G. Saade, "Timing of Indicated Late-Preterm and Early-Term Birth", Obstetrics \& Gynecology, vol. 118, no. 2, 1, pp. 323-333, 2011.

[15]M. Belfort, "Indicated Preterm Birth for Placenta Accreta", Seminars in Perinatology, vol. 35, no. 5, pp. 252-256, 2011

\section{Author Profile}

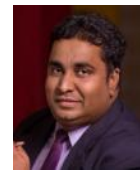

Professor HemanthaDodampahala received the M.B.B.S. (Hons) and M.S (Obstetrics and Gynaecology) from University of Colombo, Sri Lanka. He also obtained FRCOG and FRCS from United Kingdom. He is also a member of International Representative Committee RCOG and a member of International Society of Ultrasound in Obstetrics and Gynaecology. He has over 211 citations for his research work in areas of fetal brain activity, fetal disorders, interventional fetal surgery, high risk Obstetrics, recurrent miscarriages, polycystic ovarian disease and subfertility. He ranks the $18^{\text {th }}$ position in world ranking for research citations in fetal medicine. 